\title{
Apontamentos filosóficos para uma análise do esporte moderno: desdobramentos para a Educação Física
}

\section{Doutorando em Filosofia e História da Educação pela FE/Unicamp}

\section{Resumo}

Tem-se como objetivo analisar o esporte moderno, a nosso ver, como um dos objetos de conhecimento da Educação Física escolar, por meio do aporte teóricometodológico do materialismo histórico-dialético. Para tanto, enfatizou-se no aprofundamento das categorias objetivação, apropriação, humanização e alienação. Com base nessas categorias conclui-se que o esporte moderno é um fenômeno social composto por inúmeras riquezas materiais e imateriais produzidas no decorrer da história pelo conjunto dos seres humanos. Entretanto, no âmbito do modo de produção capitalista, essas riquezas são expropriadas dos seres humanos e esse fenômeno social, por sua vez, assume um caráter alienador.

Palavras-Chave: materialismo histórico-dialético; esporte moderno; educação física escolar.

\begin{abstract}
This text has as objective to analyse the modern sport, in our view, as one of the objects of knowledge of school physical education, by means of theoreticalmethodological contribution of historical materialism dialectic. For both, it was emphasized in the deepening of the categories objectification, appropriation, humanization and alienation. Based on these categories it is concluded that the modern sport is a social phenomenon consisting of numerous tangible and intangible wealth produced in the course of the story by all human beings. However, within the capitalist mode of production, these riches are expropriated of humans and this social phenomenon, in turn, assumes a alienor character.
\end{abstract}

Keywords: historical-dialectic materialism; trendy sports; school physical education.

Filosofia e Educação [rfe] - volume 7, número 3 - Campinas, SP

Outubro de 2015-Janeiro de 2016 - ISSN 1984-9605 - p. 139-169 
A possibilidade não é a realidade, mas é também ela uma realidade [...].

Gramsci (1995)

\section{Introdução}

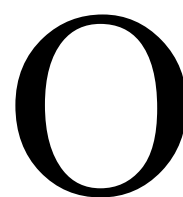

esporte moderno é, impreterivelmente, uma prática ${ }^{1}$ social. É uma prática produzida historicamente e desenvolvida socialmente pelo conjunto dos homens. Por conseguinte, essa prática deve ser compreendida como um complexo no interior de outro complexo que é a vigente sociedade, isto é, a sociedade capitalista.

Destarte, compreendemos que o esporte moderno é uma prática que tem como especificidade a institucionalização de elementos lúdicos da cultura corporal. A cultura corporal, por sua vez, é o objeto de conhecimento da Educação Física escolar que abrange as seguintes práticas corporais: o jogo, a dança, a mímica, a brincadeira, o esporte, etc.

O presente trabalho tem como objetivo analisar o esporte moderno com base nos fundamentos do materialismo histórico-dialético. Tem como recorte a explicitação de quatro categorias ${ }^{2}$ que, a nosso ver, consubstanciam a reflexão sob uma crítica substantiva às determinações e nexos do esporte moderno no interior da sociedade capitalista, isto é, referimo-nos às categorias: objetivação, apropriação, humanização e alienação.

Consideramos fulcral esse estudo, pois é por meio da explicitação de tais categorias que temos a possibilidade de compreender e analisar a cultura

1 Partimos do pressuposto de que prática não significa ações do sujeito particular. A prática que compreendemos é a prática social construída pelo conjunto dos homens no decorrer de sua história, ou seja, no decorrer da existência humana.

2 Compreendemos como categoria a expressão da máxima adestração de dado objeto, de dado movimento do real, justamente, por conter maior concreticidade (o concreto, nesse caso, é o mais abstrato na perspectiva da totalidade). Categoria, desse modo, é uma unidade de análise, ou seja, é síntese de múltiplas determinações (por isso, que ela é mais abrangente) que se desencadeia em uma produção abstrata do trabalho intelectual da capacidade humana de decodificar a realidade, o mundo real.

Filosofia e Educação [rfe] - volume 7, número 3 - Campinas, SP

Outubro de 2015-Janeiro de 2016 - ISSN 1984-9605 - p. 139-169 
humana e, assim, as suas especificidades tais como a cultura corporal e, por conseguinte, o esporte moderno.

O presente estudo percorre o seguinte caminho metodológico: 1) explicitar as categorias objetivação e apropriação - por expressar o processo de autoconstrução do ser humano no decorrer da história da humanidade para apresentarmos elementos da cultura humana e, consequentemente, da cultura corporal; 2) explicitar as categorias humanização e alienação - por expressar o caráter contraditório com que a relação objetivação e apropriação vêm ocorrendo no processo histórico da humanidade, caracterizado, atualmente, pela luta de classes.

E, com isso, dar enfoque na reflexão sobre o esporte moderno, cujo intuito se dá em analisar, conforme o aporte teórico-metodológico do materialismo histórico-dialético, o esporte moderno como uma construção humana, por meio da relação das categorias objetivação e apropriação. Contudo, exporemos, também, que essa construção humana é ofuscada pelo processo contraditório da objetivação e da apropriação no bojo da sociedade capitalista, isto é, no bojo do embate entre as classes sociais, ocasionando um processo contraditório entre as categorias humanização e alienação.

\section{Apontamentos sobre a cultura e a cultura corporal: em questão as categorias objetivação e apropriação}

Para compreendermos as categorias objetivação e apropriação sob os pressupostos do materialismo histórico-dialético é necessário refletir pela problemática do trabalho, ou seja, pela definição e pela especificidade da existência humana, tendo em vista que é pelo trabalho a única possibilidade de haver a existência humana.

É cabível salientar que o ser humano se constitui como tal pelo fato de que urge como necessidade a produção contínua de sua própria existência.

Filosofia e Educação [rfe] - volume 7, número 3 - Campinas, SP

Outubro de 2015-Janeiro de 2016 - ISSN 1984-9605 - p. 139-169 
Nesse constructo, pode-se diferenciar o ser humano dos animais: sendo que os animais têm a sua própria existência, uma vez que esta é garantida pela natureza e, com isso, eles adaptam-se ao meio natural. Já o ser humano, de acordo com Saviani (2014, p. 109, itálicos nosso), “[...] tem de fazer o contrário; ele constitui-se no momento em que necessita adaptar a natureza a si, não sendo mais suficiente se adaptar à natureza. Ajustar a natureza às necessidades, às finalidades humanas, é o que se faz pelo trabalho". Assim, completa o autor: "Trabalhar não é outra coisa senão agir sobre a natureza e transformá-la".

Ainda quanto a distinção entre os seres humanos dos demais animais, Marx (2008, p. 84, itálicos no original) assevera:

O animal é imediatamente um com a sua atividade vital. Não se distingue dela. É ela. O homem faz da sua atividade vital mesma um objeto da sua vontade e da sua consciência. Ele tem atividade vital consciente. Esta não é uma determinidade (Bestimmtheit) com a qual ele coincide imediatamente. A atividade vital consciente distingue o homem imediatamente da atividade vital animal. Justamente, [e] só por isso, ele é um ser genérico. Ou ele somente é um ser consciente, isto é, a sua própria vida lhe é objeto, precisamente porque é um ser genérico. Eis por que a sua atividade é atividade livre.

O ser humano, ao produzir, por meio do trabalho, os meios necessários para satisfazer as condições mais elementares e mais complexas de sua existência, está humanizando a sua atividade e se auto-humanizando. Segundo Duarte (2013, p. 26), “a transformação objetiva é acompanhada da transformação subjetiva. A atividade de trabalho cria, portanto, uma realidade humanizada tanto objetiva quanto subjetivamente".

Filosofia e Educação [rfe] - volume 7, número 3 - Campinas, SP

Outubro de 2015-Janeiro de 2016 - ISSN 1984-9605 - p. 139-169 
A formação humana, portanto, é calcada no trabalho e este constitui a realidade humana. Logo, a existência humana se dá pelo contínuo processo de transformação da natureza em benefício do próprio ser humano. No bojo dessa atividade, ou seja, da atividade trabalho, é que se cria a cultura, a cultura humana (o mundo humano). A cultura, nesse sentido, amplia-se progressivamente no decorrer do tempo.

Marx (2011b, p. 218), a respeito do processo de trabalho, explicita que

O processo de trabalho [...] é atividade dirigida com o fim de criar valores-de-uso, de apropriar os elementos naturais às necessidades humanas; é condição necessária do intercâmbio material entre o homem e a natureza; é condição natural eterna da vida humana, sem depender, portanto, de qualquer forma dessa vida, sendo antes comum a todas as suas formas sociais.

Aquilo que não é garantido pela natureza para a existência humana tem que ser produzido historicamente e desenvolvido socialmente pelos seres humanos e, nesse contexto, inclui a própria produção do ser humano. "Podemos, pois, dizer que a natureza humana não é dada ao homem, mas é por ele produzida sobre a base da natureza biofísica" (Saviani, 2008, p. 13).

Novamente, recorrendo a Marx (2011a, p. 05, itálicos nosso), explicitamos o fio condutor do seu estudo, que é fulcral para o nosso entendimento sobre esse processo contínuo da formação humana sob a égide materialista e histórica:

na produção social da sua existência, os homens estabelecem relações determinadas, necessárias, independentes da sua vontade, relações de produção que correspondem a um determinado grau de desenvolvimento das forças produtivas materiais. O conjunto destas

Filosofia e Educação [rfe] - volume 7, número 3 - Campinas, SP

Outubro de 2015-Janeiro de 2016 - ISSN 1984-9605 - p. 139-169 
relações de produção constitui a estrutura da sociedade, a base concreta a qual se eleva uma superestrutura jurídica e política e à qual correspondem determinadas formas de consciência social. O modo de produção da vida material condiciona o desenvolvimento da vida social, política e intelectual em geral. Não é a consciência dos homens que determina o seu ser; é o seu ser social que, inversamente, determina a consciência.

A atividade material é que possibilita ao ser humano a construção dos elementos fundamentais para a sua sobrevivência e, por conseguinte, por meio do intercâmbio entre a produção material dos homens com a linguagem da vida real ocorre a produção de ideias, de representações (de signos), da consciência. Tanto que os seres humanos são sínteses de múltiplas determinações no interior das relações sociais e seu desenvolvimento histórico ocorre de forma contínua como um ser social. Ademais, conforme consta em A ideologia alemã: "os homens, ao desenvolverem sua produção e seu intercâmbio materiais, transformam também, com esta sua realidade, seu pensar e os produtos de seu pensar" (Marx; Engels, 2007, p. 94).

A consciência, nesse caso, é a expressão ideal - no sentido de ideias do psiquismo humano. Ela desenvolve-se "graças à complexificação evolutiva do sistema nervoso central pela decisiva influência do trabalho e da linguagem, inaugurando a transformação do ser orgânico em ser social" (Martins, 2013, p. 28).

É justamente nessa esteira que devem ser compreendidas as categorias objetivação e apropriação. Isto é, essas categorias se efetivam, por meio de uma relação dialética, no interior da atividade trabalho. Nas palavras de Duarte (2013, p. 10): 
A dialética entre objetivação e apropriação faz-se presente na teoria marxista na concepção de trabalho como atividade que, em sua forma primeira e fundamental, se apresenta como transformação da natureza. Nessa atividade, os seres humanos apropriam-se da natureza e objetivam-se nos produtos do trabalho. Para que isso ocorra, é necessária, entretanto, a apropriação prévia das forças produtivas já existentes na sociedade. A dialética entre objetivação e apropriação é essencial para compreender-se a relação entre o desenvolvimento histórico da humanidade e o desenvolvimento do indivíduo.

O ser humano pela sua capacidade de transformar intencional e conscientemente a natureza circundante para seu próprio benefício cria a condição de se apropriar da natureza, a fim de transformá-la para si próprio.

Com isso, o homem objetiva-se a si próprio no interior dessa transformação. "Por sua vez, essa atividade humana objetivada nos produtos e fenômenos culturais passa a ser ela também objeto de apropriação, isto é, o ser humano deve se apropriar daquilo que de humano ele criou" (Duarte, 2013, p. 27). Essa ação faz com que ocorram novas necessidades humanas que, por conseguinte, exigem uma nova atividade específica, efetivando, assim, um processo sem fim no âmbito da formação humana.

De forma ilustrativa podemos analisar, brevemente (dada a sua complexidade), a atividade de produção de instrumentos. Essa atividade é, ao mesmo tempo, um processo de apropriação da natureza pelo ser humano e um processo de objetivação desse mesmo ser. $\mathrm{O}$ instrumento, nesse caso, não possui como única função um utensílio a ser utilizado em uma ação imediata e esporádica.

Esse elemento tem como função ir para além dessa simples ação imediata, isto é, o instrumento após ser apropriado e objetivado pelo ser humano passa a ter uma função social, "uma significação que é dada pela 
atividade social". O instrumento é "objeto que é transformado para servir a determinadas finalidades no interior da prática social. $\mathrm{O}$ ser humano cria novo significado para o objeto". Mas, para isso, esse ser necessita conhecer as propriedades dos objetos encontrados na natureza e, dessa forma, poderá analisar e dar uma finalidade aos objetos em determinada sociedade, construindo, assim, um significado social para os objetos (Duarte, 2013, p. 28).

No entanto, vale destacar que a objetivação humana não ocorre apenas pela produção de objetos materiais. Existem outras formas de se efetivar essas objetivações. Uma delas é a importante atividade, já supracitada, que imbrica no processo de formação do ser humano: a linguagem. A produção da linguagem é uma atividade relevante para as determinações que há na transformação do ser humano (orgânico) em um ser humanizado (social). Tanto que, por exemplo, a atividade de produção da linguagem atua intensamente na atividade de produção de instrumentos.

A atividade vital humana, sendo originalmente uma atividade imediatamente coletiva, exige a atividade de comunicação, que se foi objetivando, ao longo da história primitiva, em signos e em sistemas de signos, isto é, a linguagem. Esses sistemas de signos transformamse em sistemas internos, orientadores da atividade de pensamento, num processo infinito de interiorização. A apropriação da linguagem é a apropriação da atividade histórica e social de comunicação que nela se acumulou, se sintetizou (DUARTE, 2013, p. 34).

A objetivação e a apropriação geram um acúmulo de experiência, de contato e de intervenção do ser humano com a natureza. De uma síntese das potenciais capacidades que esse ser possui na atuação perante a natureza para a sua benfeitoria. Como anunciamos, essas categorias interagem 
dialeticamente e preconizam o movimento inerente da sociedade. A especificidade da atividade vital humana, por meio da objetivação e da apropriação, se efetiva com o passar do tempo como um processo de humanização da natureza e também como processo do gênero humano ${ }^{3}$.

Com efeito, esse processo do gênero humano não se constitui por meio da transmissão da herança genética do ser humano. As características do processo do gênero humano são constituídas e estabelecidas, de acordo com Duarte (2013, p. 37-38), pelo extenso e complexo movimento "do processo histórico de apropriação da natureza pela atividade social e de objetivação dos seres humanos na natureza formada".

Esse processo de objetivação e apropriação, capacidade exclusiva do ser humano, que finda no processo do gênero humano, faz com que

a atividade, ao longo da história, vai construindo as objetivações, desde os objetos stricto sensu, bem como a linguagem e as relações cotidianas entre os seres humanos, até as formas mais elevadas de objetivação humana, como a arte, a ciência e a filosofia (DUARTE, 2013, p. 38).

Assim, colocamos nesse campo de objetivação humana a educação escolar e, por conseguinte, a Educação Física escolar juntamente com os seus pressupostos e desdobramentos, ou seja, juntamente com o seu objeto de conhecimento: a cultura corporal.

É na relação dialética entre as categorias objetivação e apropriação que se deve compreender a cultura corporal que é, por sua vez, o objeto de

3 A respeito da categoria gênero humano, Duarte (2013, p. 09, itálicos nosso) esclarece que a mesma é "o resultado da história social humana, da história da atividade objetivante dos seres humanos (a formação do indivíduo é a formação do homem singular como um ser genérico, um pertencente ao gênero humano)".

Filosofia e Educação [rfe] - volume 7, número 3 - Campinas, SP

Outubro de 2015-Janeiro de 2016 - ISSN 1984-9605 - p. 139-169 
conhecimento da Educação Física escolar, tal qual preconizado pelo Coletivo de Autores (1992).

A Educação Física é uma área do conhecimento que trata, pedagogicamente, no âmbito escolar, da cultura corporal. Esta é configurada por meio de práticas corporais que constituem os conteúdos a serem transmitidos no interior das aulas de Educação Física. A reflexão desse conhecimento visa apreender essas práticas corporais como uma produção da atividade de linguagem.

O homem se apropria da cultura corporal dispondo a sua intencionalidade para o lúdico, o artístico, o agonístico, o estético ou outros, que são representações, ideias, conceitos produzidos pela consciência social e que chamaremos de 'significações objetivas' (COLETIVO DE AUTORES, 1992, p. 62).

É necessário refletir sobre a cultura corporal à luz do materialismo histórico-dialético para que, assim, possa compreendê-la na totalidade concreta, isto é, na prática social global (mundo real).Escobar (1995, p. 94) ao defender a cultura corporal como objeto de conhecimento da Educação Física, define o conceito de cultura corporal como a representação de um vasto campo da cultura que culmina na "produção de práticas expressivocomunicativas, essencialmente subjetivas que, como tal, externalizam-se pela expressão corporal". Isto é, compreende-se a cultura corporal como o acervo de ações históricas e sociais que ocorreram por meio da objetivação e da apropriação dos indivíduos ao longo da história da humanidade como ações pertinentes a fim de suprir as suas próprias necessidades.

Esse acúmulo é transferido de gerações para gerações e, nessas transferências, tais ações sofrem modificações, a fim de aperfeiçoá-las para conseguir, de uma melhor maneira, contemplar as necessidades humanas. A 
cultura corporal, nesse contexto, é definida como ações que atuam no campo simbólico e subjetivo do ser humano.

Taffarel e Escobar (2009, s.p., itálicos nossos), a respeito da relação da cultura corporal com a Educação Física, realizam as seguintes ponderações:

Faz-se evidente que o objeto de estudo da Educação Física é o fenômeno das práticas cuja conexão geral ou primigênia - essência do objeto e o nexo interno das suas propriedades - determinante do seu conteúdo e estrutura de totalidade é dada pela materialização em forma de atividades - sejam criativas ou imitativas - das relações múltiplas de experiências ideológicas, políticas, filosóficas e outras, subordinadas à leis histórico-sociais. O geral dessas atividades é que são valorizadas em si mesmas; seu produto não material é inseparável do ato da produção e recebe do homem um valor de uso particular por atender aos seus sentidos lúdicos, estéticos, artísticos, agonísticos, competitivos, e outros, relacionados à sua realidade e às suas motivações. Elas se realizam com modelos socialmente elaborados que são portadores de significados ideais do mundo objetal, das suas propriedades, nexos e relações descobertos pela prática social conjunta. A essa área de conhecimento que se constrói a partir dessas atividades, no momento, a denominamos de "Cultura Corporal", não obstante seja alvo de críticas por "sugerir a existência de tipos de cultura". Pensamos não haver necessidade de polemizar a tal respeito, apenas queremos destacar que, para toda interpretação, deve prevalecer a conceituação materialista histórico-dialética de cultura.

Em epítome, compreendemos que por meio do processo de objetivação e apropriação efetiva-se a essência do ser humano, e no bojo desse processo ocorrem as atividades oriundas da cultura corporal. Essa efetivação se dá tanto no próprio processo do gênero humano quanto no 
indivíduo singular. A dinâmica estabelecida nessa relação objetivaçãoapropriação ocorre de maneira abrangente e por meio de diversos elementos e determinações históricas e sociais, entre elas, conforme já afirmamos, a cultura corporal.

A cultura corporal parte da categoria trabalho enquanto atividade humana produtiva de suas condições objetivas e subjetivas de existência, onde a cultura é produto da atividade do ser humano e das relações que estabelece com os demais (FRIZZO, 2013, p. 203-204).

Portanto, o ser humano, para se tornar humano, precisa objetivar-se do emaranhado de atividade já estabelecido por outros seres humanos para poder inserir-se nesse processo histórico.

Concluímos que a relação entre as categorias objetivação e apropriação atua como dinâmica interna do processo histórico-social de humanização do gênero humano. É o conjunto de atividades dos seres humanos "que efetiva a objetivação do gênero humano em níveis cada vez mais universais" (Duarte, 2013, p. 53-54).

Todavia, veremos a seguir, ao explicitarmos as categorias humanização e alienação, que o processo do gênero humano - diga-se a relação apropriação e objetivação -, no âmago do modo de produção capitalista, preconiza intensamente a formação do ser humano por meio de uma lógica adaptativa, passiva e fragmentada. Inclusive, o esporte moderno comunga por essa lógica. E sobre essa inquirição argumentaremos subsequentemente. 
3. O esporte moderno no interior do modo de produção capitalista: em questão as categorias humanização e alienação

A efetivação da relação entre objetivação e apropriação assume um caráter essencial no processo de humanização. Entretanto, Duarte (2013, p. 55) adverte que a compreensão da relação objetivação e apropriação, por si mesma, se dá apenas no plano da abstração e, "por si só, ainda não permite a plena compreensão da concretude histórica da formação tanto do gênero humano quanto dos indivíduos".

Para avançar além dessa abstração - que, por sua vez, não deixa de ser menos importante - rumo à concretude, dando ênfase às diversas relações e determinações, é necessário compreender "a relação entre objetivação e apropriação no interior da luta de classes; isto é, do longo período histórico que se estende até a atualidade" (Duarte, 2013, p. 55). Ao abranger a luta de classes, tomando como pressuposto a relação dialética entre objetivação e apropriação (o processo de gênero humano e a formação do indivíduo singular), faz-se indispensável abordar a categoria humanização (como síntese das múltiplas determinações efetivadas pela relação da objetivação e da apropriação) e, no intento do modo de produção capitalista, na sua relação com a categoria alienação.

No seio do atual modo de produção, ou seja, da sociedade capitalista, a alienação assume um papel relevante na sua relação com o processo de humanização dos seres humanos, uma vez que a essência magna dessa sociedade é a exploração do indivíduo em proveito de uma baixa camada da sociedade. A alienação contribui ou impossibilita que as características essenciais do gênero humano e, assim, do processo de humanização do ser humano, se concretizem para uma ou para outra classe social.

Konder (2009, p. 29, itálicos no original) afirma que "uma primeira causa dessa deformação monstruosa se encontra na divisão social do 
trabalho, na apropriação privada das fontes de produção, no aparecimento das classes sociais". Na atual sociedade é impossível que o caráter social da atividade humana se direcione a uma "socialidade para si", fazendo com que os indivíduos tenham o controle consciente, coletivo e livre dos produtos produzidos histórica e socialmente por outros indivíduos. Tendo em vista que

As condições criadas pela divisão do trabalho e pela propriedade privada introduziram um "estranhamento" entre o trabalhador e o trabalho, uma vez que o produto do trabalho, antes mesmo de o trabalho se realizar, pertence a outra pessoa que não o trabalhador (KONDER, 2009, p. 30).

A relação dialética entre objetivação do processo de gênero humano e a apropriação dos produtos sociais diante das determinações do modo de produção capitalista ocorre por meio da humanização no interior das relações sociais alienadas.

A alienação, nesse caso,é um fenômeno inteiramente histórico-social e concreto. É um processo no modo de produção capitalista que apresenta um antagonismo bem definido, isto é: a classe trabalhadora é subsumida, impedida ou, em última instância, limitada de ter acesso às máximas possibilidades da vida humana produzidas histórica e socialmente por gerações passadas.

O ser humano aliena-se perante as forças essenciais humanas efetivamente existentes porque as relações sociais, nas quais se realizam a objetivação e apropriação dessas forças essenciais, são relações que são postas, pelos seres humanos e aos seres humanos, como relações naturais, não como produtos da atividade social, não

Filosofia e Educação [rfe] - volume 7, número 3 - Campinas, SP

Outubro de 2015-Janeiro de 2016 - ISSN 1984-9605 - p. 139-169 
como algo que possa ser transformado por seus criadores, os seres humanos (DUARTE, 2013, p. 60).

Em sua gênese, a alienação, efetiva-se pelo fato de que o ser humano não possui o domínio de maneira coletiva (frisa-se o caráter coletivo) dos elementos e das determinações das relações sociais, com isso, é submetido a essas relações como se elas fossem um poder transcendental, superior, estranho aos indivíduos. As relações sociais, no modo de produção capitalista, têm a capacidade em efetivar essa possibilidade de domínio sobre os indivíduos. Nessa questão há uma contradição - em meio a diversas contradições que "alimentam" a sociedade da ordem do capital muito bem sintetizada por Duarte (2013, p. 60):

O ser humano vê-se dominado, explorado, humilhado e até morto pelas relações sociais que foram criadas pela própria humanidade. Ao mesmo tempo, o ser humano cria possibilidades de uma vida plena de sentido e dignidade, repleta de conteúdo e desenvolvimento, em suma, uma vida livre e universal. Mas essas possibilidades pouco ou nada se concretizam na vida da maior parte das pessoas.

Tudo aquilo que é objetivado e o que foi apropriado dessa objetivação são instaurados como elementos ocultos, estranhados da classe trabalhadora. Há uma alienação, um estranhamento daquilo que foi e é produzido pela própria classe trabalhadora.

Marx (2008, p. 80), nos Manuscritos de 1844, ao explicar essa relação contraditória existente sobre a produção do objeto feita pelo trabalhador e a sua relação com este, seguindo as determinações de alienação da sociedade capitalista, explicita: 
Este fato nada mais exprime, senão: o objeto (Gegenstand) que o trabalho produz, o seu produto, se lhe defronta como um ser estranho, como um poder independente do produtor. O produto do trabalho é o trabalho que se fixou num objeto, fez-se coisal (sachlich), é a objetivação (Vergegenständlichung) do trabalho. A efetivação (Verwirklichung) do trabalho é a sua objetivação. Esta efetivação aparece ao estado nacional-econômico como desefetivação (Entwirklichung) do trabalhador, a objetivação como perda do objeto e servidão ao objeto, apropriação como estranhamento (Entfremdung), como alienação (Entäusserung).

Quanto mais o indivíduo (o trabalhador) se apropria das objetivações do mundo externo a ele, pelo seu trabalho, mais esse trabalhador se torna desprovido do acesso aos seus meios de vida. Adapta o trabalhador ao fato de que somente ele, enquanto trabalhador, consegue manter-se um sujeito físico, meramente em proveito da "tentativa" de sobrevivência enquanto um "sujeito físico". Aqui encontramos a contradição inerente à possibilidade de humanização e a "prevalência" da alienação do trabalhador: "quanto mais o trabalhador produz, menos tem para consumir; [...] quanto mais valores cria, mais sem-valor e indigno ele se torna" (Marx, 2008, p. 82).

A atividade vital consciente do homem, nesse caso, deixa de ser uma atividade que contribua com a sua essência, preconizando apenas as suas ações para buscar sanar as necessidades meramente da sua existência, isto é, há uma inversão da possibilidade de compreender o ser humano como um ser consciente genérico.

Em síntese, a apropriação e objetivação dos elementos da natureza pelo ser humano, no modo de produção capitalista, surge alienada ao trabalhador, e a produção do objeto - extraído da natureza - é, também, alienada ao trabalhador. 
Insistimos em dizer: a alienação está a todo o momento na articulação entre atividade trabalho e os pressupostos oriundos da ordem do capital, do modo de produção capitalista. A classe trabalhadora tem os produtos alienados de si mesma, ou melhor, esse produto "torna-se algo alheio, estranho, exterior e hostil a ela, em uma palavra, torna-se capital" (Duarte, 2013, p. 73).

Ademais, a relação entre objetivação e apropriação, o cerne da atividade humana "caracteriza a especificidade do mundo da cultura diante do mundo da natureza", com efeito, na atual sociedade fracionada por classes "tanto a objetivação quanto a apropriação do que foi objetivado são marcadas pela contradição entre humanização e alienação" (Duarte, 2013, p. 69).

Com tais aprofundamentos, no que se refere à compreensão da relação dialética entre objetivação e apropriação e como essa relação se dá no seio do modo de produção capitalista - na relação da humanização e da alienação -, passamos a analisar uma das atividades da cultura corporal, isto é, o esporte moderno.

O esporte moderno, por sua vez, é um fenômeno social que explicita, por um lado, as grandes possibilidades que o indivíduo possui em decodificar o mundo real, ou seja, as diversas possibilidades criadas pelo conjunto dos homens na sua relação com a natureza. Contudo, no âmago da prática social orientada pelos pressupostos do capitalismo, o esporte moderno torna-se um fenômeno que atua, impreterivelmente, no embate das lutas de classe.

Evidencia-se, por conseguinte, a alienação dos bens culturais para a maior parcela dos seres humanos (para a classe trabalhadora). Parafraseando Bracht (2005): todo gol ou ponto conquistado no esporte é, nada mais, do que um gol ou ponto contra a classe trabalhadora. A possibilidade dessa 
classe de se humanizar, apropriando-se das máximas produções humanas, é aviltada pelos desdobramentos da sociedade capitalista e, assim, também, do esporte moderno.

O fenômeno esporte tem, portanto, que ser compreendido como uma atividade, inerentemente, histórico-social que sofre modificações sob dadas condições do modo de organizar os bens culturais materiais e imateriais dos seres humanos. Tal condição não pode ser compreendida de maneira isolada, mas sim de forma histórica e totalitária, no qual configura a espécie humana, ou seja, o gênero humano. É dessa forma que as práticas corporais e, assim, o esporte moderno é construído, consolidado e sistematizado. Isto é, por meio das relações de produção da vida humana (Taffarel, 2010).

Destarte, caracterizamos o esporte moderno como uma atividade humana que compõe o acervo de atividades da categoria cultura corporal. Essa atividade tem como especificidade o "caráter competitivo surgida no âmbito da cultura europeia por volta do século XVIII, e que com esta, expandiu-se para o resto do mundo" (Bracht, 2005, p. 13).

O surgimento do esporte moderno se deu na síntese de um processo de modificação dos elementos lúdicos da cultura corporal, oriunda, principalmente, das classes populares inglesas. Essa modificação atuou no campo da institucionalização de signos e códigos que deram um caráter esportivo aos jogos populares.

O esporte moderno, imbricado na institucionalização de signos e códigos, assumiu características específicas para a sua prática, tais como: “competição, rendimento físico-técnico, record, racionalização e cientificização do treinamento" (Bracht, 2005, p. 14).

Assumindo essas especificidades, o esporte moderno percorreu, basicamente, o processo de expansão da modernidade, ou seja, da expansão da sociedade capitalista. Para Coelho Jr. et al. (2010), sob as condições 
supracitadas, o esporte moderno pode ser compreendido como um reflexo dos valores, mais gerais e funcionais, do modo de produção capitalista. Aderindo, por esse mote, à contribuição para a manutenção do status quo.

O esporte moderno, no bojo das especificações do modo de produção capitalista, atua: como um sistema que ocorre por meio de ações coisificadas (alienadas) em acordo com o trabalho - pelo seu valor de uso subsumido ao valor de troca; como um elemento que atua na repressão das necessidades sociais; como um fenômeno manipulador e adaptativo.

Concordamos com Iasi $(2014$, s/p.) ao exemplificar as sensações e as compreensões do futebol e, dessa forma, trazemos à tona para a reflexão do esporte moderno:

O futebol é um esporte. Para quem pratica e para quem assiste costuma ser muito apaixonante e cumpre funções bem interessantes. Por exemplo, podemos sofrer, nos alegrar, chegar à exaltação, por motivos absolutamente irrelevantes: uma bola que passou perto, a polêmica marcação de uma penalidade, uma jogada de efeito ou mesmo uma absolutamente ridícula, uma cena magistral da mais pura arte que resulta em gol ou um caos de corpos e acidentes que culminam na bola rolando indolente ao cruzar a linha sob o olhar de milhares de pessoas.

Dito isso, e como já afirmarmos, o esporte na sociedade hodierna é, também, uma mercadoria. Sendo, a realização de mais valor dessa mercadoria que a mesma se torna relevante para o capitalismo, ou seja, pela valorização do capital."Desta maneira é espetáculo, não em seu conteúdo substantivo (nos elementos que o constituem como esporte ou na paixão que provoca), mas em sua própria forma" (Iasi, 2014, s/p.).

Filosofia e Educação [rfe] - volume 7, número 3 - Campinas, SP

Outubro de 2015-Janeiro de 2016 - ISSN 1984-9605 - p. 139-169 
O esporte moderno assume um caráter alienador, porque é um elemento social que tem como uma das suas funções contribuir na estabilização (ou na equalização) social. Eis como possibilidade por parte do esporte moderno a sinuosidade da atenção dos seres humanos frente às condições sociais e, por conseguinte, como um atenuador dos conflitos sociais, ou seja, por uma tentativa de apaziguamento entre as classes sociais - tentando, assim, compensar as desumanas condições de vida em que a maioria dos seres humanos vive. Ademais, conforme Bracht (2005, p. 30), o esporte moderno contribui no desvio da compreensão da "agressividade potencial das suas origens sociais para as ações esportivas".

Outro postulante comum ao esporte moderno é a função ideológica em proveito da igualdade de chances no esporte, ou melhor, equiparando as condições objetivas da prática esportiva. "A igualdade formal de chances da estrutura esportiva indica para a presumível existência de uma correspondente forma de sociedade" (Bracht, 2005, p. 31). Tal condição preconiza para o quinhão da igualdade social, ou seja, contribui na (impossível) negação da desigualdade e no embate que há entre as classes sociais. Promulgando, consequentemente, para a formação do ser humano o princípio de igualdade no interior da sociedade capitalista. ${ }^{4}$

4 Todavia, podemos indicar, à guisa de exemplo, as obras de Andrew Jennings (2011; 2014), repórter investigativo escocês, que apresenta um relato referente às inúmeras ações ilegais da macro instituição do futebol mundial, a Federação Internacional de Futebol (FIFA), e, consequentemente, do seu presidente, Joseph Blatter. Essas obras apresentam diversas ações "legais e ilegais" realizadas por Blatter em prol da acumulação de capital, porém tais acusações comprovadas (via documentos, relatos etc.) são banalizadas, ou seja, naturalizando ações desiguais em um modo de produção desigual. A tal ponto que as informações coletadas e comprovadas por Andrew Jennings em nada interferiram no andamento da FIFA, do seu presidente e de suas intervenções em todo o mundo. Inclusive o presidente, denunciado por Jennings, continua no poder (e, no atual momento, sendo investigado por mais denúncias a respeito de movimentações "fraudulentas" no bojo da instituição supracitada).

Filosofia e Educação [rfe] - volume 7, número 3 - Campinas, SP

Outubro de 2015-Janeiro de 2016 - ISSN 1984-9605 - p. 139-169 
O esporte moderno como elemento social, que atua no seio do modo de produção capitalista, fomenta, também, as condições de consumo de vários bens de consumo produzidos atualmente pela sociedade involucral, no qual promove o descartável e o supérfluo. Portanto, o esporte moderno contribui para a Era da Sociedade do Entertainment, fazendo "aflorar, com toda evidência, o sentido de desperdício e de superfluidade que caracteriza a lógica societal contemporânea" (Antunes, 2005, p. 35).

Destarte, na vigência desse atual momento societal, as práticas corporais - e, portanto, o esporte moderno - são vendidas em benefício, principalmente, da massificação das práticas corporais como mercadorias, adotando, assim, a segmentação da oferta dessas práticas e, assim, há uma “obsolescência planejada pela qual passam as práticas corporais, sendo renovadas e modificadas em sua superfície de forma cada vez mais rápida [supérflua]" (Vivan, 2010, p. 12).

Esse desdobramento, no qual o esporte moderno apresenta condições objetivas para tal efetivação, incentiva a naturalização de padrões alienantes através dos mais variados mecanismos sociais, como, por exemplo, os traços constitutivos das atuais especificidades ${ }^{5}$ do modo de produção hodierno, ou seja, como "um processo de organização do trabalho cuja finalidade essencial, real, é a intensificação das condições de exploração da força de trabalho" (Antunes, 2009, p. 54-58, itálicos no original): a) o mercado de trabalho assume a característica do trabalho operário em "equipe”, com

5 Nos referimos à produção calcada nos fundamentos toyotista. No qual, de acordo com Antunes $(2009$, p. 60 , itálicos no original), "A vigência do neoliberalismo, ou de políticas sob sua influência, propiciou condições em grande medida favoráveis à adaptação diferenciada de elementos do toyotismo no Ocidente. Sendo o processo de reestruturação produtiva do capital a base material do projeto ideopolítico neoliberal, a estrutura sob a qual se erige o ideário e a pragmática neoliberal [...]". Para um aprofundamento dessa temática, no âmbito da educação, sugerimos as seguintes obras: Anderson (2012); Coggiola (1997); Frigotto (2010); Gentili (2002); Harvey (2012); Hobsbawn (2009); Lombardi, Saviani e Sanfelice (2005); Sader e Gentili (2012); Wood (2015), entre outros.

Filosofia e Educação [rfe] - volume 7, número 3 - Campinas, SP

Outubro de 2015-Janeiro de 2016 - ISSN 1984-9605 - p. 139-169 
"multivariedade" de tarefas, e no esporte assume a necessidade do trabalho em equipe (mesmo em esportes individuais, mas que há indivíduos que atuam direta e/ou indiretamente no desempenho do atleta), cujo intuito se dá na máxima performance em todos os fundamentos e quesitos para a realização de gestos e ações em prol da excelência; b) no mercado de trabalho a estruturação em um processo produtivo flexível e no esporte a necessidade do treinamento e na execução de inúmeras funções, isto é, o famoso atleta completo (com inúmeras quebras de record, elevado grau de performance, etc.); entre outras.

Nesse sentido, vale expor uma passagem d'A ideologia alemã, no qual configura esse falseamento das relações sociais no sentido de equalizar e naturalizar o processo alienador e, por conseguinte, de expropriação do humano em proveito apenas da classe dirigente da sociedade:

As ideias da classe dominante são, em cada época, as ideias dominantes, isto é, a classe que é a força material dominante da sociedade é, ao mesmo tempo, sua força espiritual dominante. A classe que tem à sua disposição os meios de produção material disposição os meios de produção espiritual, de modo que a ela estão submetidos aproximadamente ao mesmo tempo os pensamentos daqueles aos quais faltam os meios da produção espiritual (MARX; ENGELS, 2007, p. 47, itálicos no original).

Outra condição preconizada pelo esporte moderno, que exemplifica a explanação acima, é a possibilidade de desviar o interesse da formação da consciência política da classe trabalhadora. Uma vez que "o interesse nas tabelas dos campeonatos, nos ídolos esportivos etc. impediria a formação da consciência política e o consequente engajamento político". Por tais consequências, "a prática do esporte levaria à adaptação às normas e ao 
comportamento competitivo, básicos para a estabilidade e/ou reprodução do sistema capitalista" (Bracht, 2005, p. 31). ${ }^{6}$

O que nos fica evidente, em relação à função ideológica conservadora ou em função da constante tentativa e consolidação de culminar os interesses da classe dominante nas "entranhas" dos trabalhadores, pela perspectiva parcial inevitável das classes sociais - utilizando a caracterização de ideologia de Goldmann (1979) -, é que cabe ao esporte moderno, na atual sociedade, persistir e contribuir com a necessidade oriunda da ordem do capital.

É preciso [para o esporte moderno] manter ocupada a atenção das maiorias de tal forma que ela mantenha sua atividade intelectual nos marcos da 'produção do consenso' que as escraviza socialmente enquanto potencializa seu gozo efêmero (OURIQUES, 2010, p. 05).

Destarte, o esporte moderno, caracterizado como uma atividade subjetiva do ser humano historicamente elaborado e socialmente desenvolvido, no seu percurso histórico, se tornou - assim como o ser humano no modo de produção capitalista - uma mercadoria. Aderindo a um caráter tecnicista, competitivo em que predomina o sobrepujar a si e aos outros indivíduos.

Portanto, é necessário, no âmbito da Educação Física escolar, apresentar elementos didático-metodológicos que culminem na

6 Ainda no limiar do futebol, ao enfatizarmos essa questão, podemos observar a tentativa de uma equalização social que ocorreu durante a Copa da FIFA no Brasil em 2014. Em contraponto, vale a afirmação de Iasi $(2014$, s/p., itálicos nosso) a seguir arrolada: "O megaevento, a Copa da FIFA, é só a potencialização desta forma mercadoria levada ao máximo, com seus negócios, interesses, investimentos, mercados milionários, a indústria do turismo e outras que passam a ocupar a centralidade que antes o jogo ocupava. Soma-se a este fato a conjuntura em que ocorrem os jogos e sua utilização política como são famosos os exemplos das olimpiadas na Alemanha nazista e a Copa do Mundo na Argentina em 1978 na época da ditadura militar".

Filosofia e Educação [rfe] - volume 7, número 3 - Campinas, SP

Outubro de 2015-Janeiro de 2016 - ISSN 1984-9605 - p. 139-169 
compreensão da essência do esporte moderno, ou seja, na sua gênese e no processo de transformação que ocorre constantemente no interior da sociedade capitalista. É necessário, balizado no materialismo históricodialético, partir das múltiplas manifestações que são representadas na intuição sensível (empírica) e, efetivar uma análise que identifique os elementos, os componentes, as determinações, os nexos; para que, assim, possa elaborar uma possível síntese compreensiva, no qual irá proporcionar, no âmbito do pensamento, o concreto real identificado no conceito de “esporte moderno".

Dessa maneira, torna-se possível ir para além da construção de pseudoconceitos, pseudoconhecimentos para análise mais fidedigna possível do esporte na realidade concreta que compõe o mundo real. É indispensável compreender o esporte moderno e seus desdobramentos sociais não apenas no aspecto prático-utilitário, ou melhor, no aspecto da intuição sensível (fenomênica) da sua especificidade, mas sim na sua totalidade concreta no interior da sociedade capitalista e do seu modo de produção (Kosik, 2010).

Trata-se, de acordo com Sánchez Vázquez (2011, p. 155), “[...] não de criar a consciência de um fato existente, mas, sim, de derrubar o que existe, de transformar as coisas". Portanto, trata-se não de compreender o esporte moderno na sua aparência - por meio de pseudoconhecimentos - mas, sim de ir à raiz dos nexos e determinações do esporte moderno para poder analisá-lo na sua plenitude e, destarte, compreender e transformá-lo em prol dos interesses da classe trabalhadora.

A práxis ordenada e regulamentada sob a égide dos interesses da classe dominante está situada em uma realidade social que"[...] é historicamente determinada e unilateral, é a praxis (sic.) fragmentária dos indivíduos, baseada na divisão do trabalho, na divisão da sociedade em 
classes e na hierarquia de posições que sobre ela se ergue" (Kosik, 2010, p. 14 , itálicos no original).

Guiamo-nos, então, segundo Saviani (2015, p. 129), pela premissa expressa "no aforismo 'sem dominar o que os dominantes dominam os dominados não chegam a se libertar da dominação"”. Para isso, em conformidade com o autor, é necessário realizar um trabalho que se deve configurar em dois momentos concomitantes e organicamente articulados: "um momento negativo que consiste na crítica à concepção dominante representada pela ideologia burguesa; e um momento positivo que implica o domínio dos instrumentos teóricos e práticos necessário à transformação social".

É por meio desse processo que a educação escolar e, consequentemente, a Educação Física (como componente curricular) devem desempenhar no processo de formação humana, no âmago da atual sociedade. Ou seja, devem desempenhar um

papel estratégico e indispensável porque, se a crise estrutural propicia as condições objetivas favoráveis à transição, para operar nessas condições não deixando escapar a oportunidade histórica de transformação estrutural, se impõe preencher as condições subjetivas que implicam uma aguda consciência da situação, uma adequada instrumentalização técnica que possibilite uma ação eficaz (SAVIANI, 2015, p. 130).

Determinando essa função para a escola e seus componentes escolares, torna-se possível efetivar ações que permitam os indivíduos, inseridos nesse processo de formação, compreenderem a realidade concreta na sua máxima possibilidade. Levando como pressuposto a capacidade de que o ser humano, no decorrer da história, desenvolveu e vem 
desenvolvendo elementos para a sua individualidade. Porém, na sociedade capitalista o tipo de individualidade, na acepção de Duarte (2013), corresponde à "essência" de indivíduos particular e concreto, uma vez que a forma de universalidade nessa sociedade se dá pela propriedade privada das forças produtivas e do conhecimento, pelo valor de troca, pela mercadoria, entre outros.

Destarte, eis como necessário perspectivar e intervir de maneira concreta para a superação dessa sociedade, pois é por meio dessa transição e efetivação de uma nova sociedade. A extinção dessa sociedade possibilita o desenvolvimento da individualidade livre e universal, intitulada por Duarte (2013) de individualidade universal concreta.

Para isso, os indivíduos devem se apropriar do conhecimento na sua forma mais elaborada, ou seja, do conhecimento historicamente sistematizado. A educação escolar (e a Educação Física) é lócus da transmissão dessa formatação de conhecimento. Portanto, o esporte moderno, um dos objetos de conhecimento da Educação Física escolar, deve ser refletido por meio de "uma adequada fundamentação teórica que permita uma ação coerente e uma satisfatória instrumentalização técnica que possibilite uma ação eficaz" (Saviani, 2015, p. 130), para que, assim, por meio do trabalho educativo, no trato do conhecimento do esporte moderno, estabeleça-se uma consistente teoria de cunho pedagógico que construa e sistematize "os elementos garantidores dos três aspectos mencionados: aguda consistência da realidade, fundamentação teórica coerente e instrumentalização técnica eficaz" (Saviani, 2015, p. 130).

\section{Considerações finais}

O presente trabalho teve como objetivo analisar o esporte moderno, por meio do aporte teórico-metodológico do materialismo histórico-dialético. 
Para tanto, explicitamos, no primeiro momento, a relação das categorias objetivação e apropriação, por compreendermos que é por meio dessas categorias que o ser humano tem a capacidade de produzir as condições necessárias para a sua sobrevivência. Nesse contexto, o ser humano (na sua relação com a natureza) produziu e produz diversos bens culturais. Entre eles situamos a cultura corporal que é um amplo campo da cultura, no qual se encontra a produção das práticas expressivo-comunicativas subjetivas, externalizadas pela expressão corporal.

No segundo momento adentramos na reflexão das categorias humanização e alienação, por expressar o caráter contraditório que há no processo de objetivação e apropriação que vem ocorrendo no atual momento histórico da humanidade, ou seja, na sociedade capitalista. Ao explicitar esse processo, pontuamos o esporte moderno como um dos diversos elementos sociais que atuam em contribuição da manutenção do status quo.

Concluímos que o esporte moderno, seguindo essas atribuições, assume um caráter alienador, atuando, dessa forma, como uma produção humana que atende a ideologia do reino do capital. Assim, ocorre, segundo Iasi (2014), uma mágica ideológica de propulsionar o interesse particular como se fosse um interesse comum ou interesse geral.

Há, portanto, a necessidade de um avanço nas reflexões e nas proposições críticas para a transformação do esporte moderno, objetivandoo como um elemento social que contribua para o movimento, em nível planetário, de luta contra a alienação e expropriação do humano dos bens culturais produzidos histórica e socialmente pelo conjunto dos homens. Nesse mote, a Educação Física escolar deve estar em consonância com essa tratativa, isto é, estar articulada com a luta da classe trabalhadora pela superação do capitalismo em proveito da implantação do socialismo. 


\section{Referências}

ANDERSON, P. Espectro: da direita à esquerda no mundo das ideias. São Paulo: Boitempo, 2012.

ANTUNES, R. L. C. Trabalho e superfluidade. In: LOMBARDI, J. C.;

SAVIANI, D.; SANFELICE, J. L. (Orgs.). Capitalismo, trabalho e educação.3. ed. Campinas: Autores Associados, HISTEDBR, 2005. p. 35-44. . Os sentidos do trabalho: ensaio sobre a afirmação e a negação do trabalho.

2. ed. 10. reimpr. São Paulo: Boitempo, 2009.

BRACHT, V.Sociologia crítica do esporte:uma introdução. 3. ed. Ijuí: Unijuí, 2005.

BREILH, J.; MATIELLO JR., E.; CAPELA, P. A globalização e a indústria do esporte: saúde ou negócio?. In: MATIELLO JR.; CAPELA, P.; BREILH, J. (Orgs.). Ensaios alternativos latino-americanos de educação física, esportes e saúde. Florianópolis: Copiart, 2010. p. 15-41.

COELHO JR. et al. Uma outra cultura esportiva é possível: críticas e alternativas ao movimento olímpico internacional. In: MATIELLO JR.; CAPELA, P.; BREILH, J. (Orgs.). Ensaios alternativos latino-americanos de educação física, esportes e saúde. Florianópolis: Copiart, 2010. p. 42-54.

COGGIOLA, O. (Org.). Globalização e socialismo. São Paulo: Xamã, 1997. COLETIVO DE AUTORES. Metodologia do ensino de educação física. São Paulo: Cortez, 1992.

DUARTE, N. A individualidade para si: contribuição a uma teoria históricocrítica da formação do indivíduo. 3. ed. Campinas: Autores Associados, 2013. ESCOBAR, M. O. Cultura corporal na escola: tarefas da educação física. Revista Motrivivência, Florianópolis, ano VII, n. 08, p. 93-102, dez. 1995. FRIGOTTO, G. Educação e a crise do capitalismo real. 6. ed. São Paulo: Cortez, 2010. 
FRIZZO, G. F. E. Objeto de estudo da educação física: as concepções materialistas e idealistas na produção de conhecimento. Revista Motrivivência, Florianópolis, ano XXV, n. 40, p. 192-206, jun. 2013.

GENTILI, P. (Org.). Pedagogia da exclusão: crítica ao neoliberalismo em educação. 10. ed. Petrópolis: Editora Vozes, 2002.

GOLDMANN, L. Dialética e cultura.2. ed. Rio de Janeiro: Paz e Terra, 1979. GRAMSCI, A. Concep̧são dialética da histórica. 10. ed. Rio de Janeiro: Civilização Brasileira, 1995.

HARVEY, D. Condição pós-moderna: uma pesquisa sobre as origens da mudança cultural. 22. ed. São Paulo: Loyola, 2012.

HOBSBAWM, E. Era dos extremos: o breve século XX: 1914-1991. 2. ed. 41. reimpr. São Paulo: Companhia das letras, 2009.

IASI, M. Não vai ter Copa! Blog da Boitempo, 2014. s/p. Disponível em: <http://blogdaboitempo.com.br/2014/02/12/nao-vai-ter-copa/>. Acesso em: 18 jun. 2014.

JENNINGS, A. Jogo sujo: o mundo secreto da FIFA: compra de votos e escândalo de ingressos. São Paulo: Panda Books, 2011. . Um jogo cada vez mais sujo: o padrão FIFA de fazer negócios e manter tudo em silêncio. São Paulo: Panda Books, 2014.

KONDER, L. O que é dialética? 28. ed. 8. reimpr. São Paulo: Brasiliense, 2009. KOSIK, K. Dialética do concreto. 2. ed. 8. reimpr. Rio de Janeiro: Paz e Terra, 2010.

LOMBARDI, J. C.; SAVIANI, D.; SANFELICE, J. L. (Orgs). Capitalismo, trabalho e educação. 3. ed. Campinas: Autores Associados, HISTEDBR, 2005.

MARTINS, L. M. O desenvolvimento do psiquismo e a educação escolar:contribuições à luz da psicologia histórico-cultural e da pedagogia histórico-crítica. Campinas: Autores Associados, 2013.

MARX, K. Manuscritos econômico-filosóficos.1. ed. 2. reimpr. São Paulo: Boitempo, 2008.

Filosofia e Educação [rfe] - volume 7, número 3 - Campinas, SP

Outubro de 2015-Janeiro de 2016 - ISSN 1984-9605 - p. 139-169 
Contribuição à crítica da economia política. 4. ed. São Paulo: Martins Fontes, 2011a.

O capital: crítica da economia política. Livro 01. Vol. 01. 29. ed. Rio de Janeiro: Civilização Brasileira, 2011b.

MARX, K.; ENGELS, F. A ideologia alemã. São Paulo: Boitempo, 2007. . Cultura, arte e literatura: textos escolhidos. 2. ed. São Paulo: Expressão

Popular, 2012.

OURIQUES, N. Esporte e política. In: MATIELLO JR.; CAPELA, P.;

BREILH, J. (Orgs.). Ensaios alternativos latino-americanos de educaşão física, esportes e saúde. Florianópolis: Copiart, 2010. p. 03-06.

SADER, E.; GENTILI, P. (Orgs.). Pós-neoliberalismo: as políticas sociais e o

Estado democrático. 1. ed. 11. reimpr. Rio de Janeiro: Paz e Terra, 2012.

SÁNCHEZ VÁZQUEZ, A. Filosofia da práxis.2. Ed. Buenos Aires: CLACSO;

São Paulo: Expressão Popular, 2011.

SAVIANI, D. Pedagogia histórico-crítica: primeiras aproximações. 10. ed.

Campinas: Autores Associados, 2008.

Politecnia e formação humana. In: SAVIANI, D. O lunar de sepé: paixão, dilemas e perspectivas na educação. Campinas: Autores Associados, 2014. pp. 109-124.

- A pedagogia histórico-crítica, as lutas de classes e a educação escolar.

In: SAVIANI, D. História do tempo e tempo da história: estudos de historiografia e história da educação. Campinas: Autores Associados, 2015. pp. 105-131.

TAFFAREL, C. N. Z. Sobre o sistema de complexos homem-esporte-saúde: reflexões a partir de contribuições da Alemanha. In: MATIELLO JR.;

CAPELA, P.; BREILH, J. (Orgs.). Ensaios alternativos latino-americanos de educação física, esportes e saúde. Florianópolis: Copiart, 2010. p. 159-183.

TAFFAREL, C. N. Z.; ESCOBAR, M. O. Cultura corporal e os dualismos necessários a ordem do capital. Boletim Germinal, n. 09, 11/2009. s/p.

Filosofia e Educação [rfe] - volume 7, número 3 - Campinas, SP

Outubro de 2015-Janeiro de 2016 - ISSN 1984-9605 - p. 139-169 
Disponível em: <http://www.uel.br/revistas/germinal/n9-

112009.htm\#7cultura >. Acesso em: 23 mai. 2013.

VIVAN, R. P. Mercantilização das práticas corporais e metamorfoses no trabalho:um

estudo sobre o setor de Fitness e bem-estar. 2010. 104f. Dissertação de Mestrado (Mestrado em Educação). Programa de Pós-Graduação em

Educação, Universidade Federal do Paraná, Curitiba, 2010.

WOOD, E. M. Democracia contra capitalismo: a renovação do materialismo

histórico. 1. ed. 2. reimpr. São Paulo: Boitempo, 2015. 